\title{
Extended approach or usage of nasoseptal flap is a risk factor for olfactory dysfunction after endoscopic anterior skullbase surgery: results from 928 patients in a single tertiary center*
}

\author{
Min Young Seo 1,2, Do-Hyun Nam³, Doo-Sik Kong ${ }^{3}$, Seung Hoon Lee', \\ Yangseop Noh², Yong Gi Jung ${ }^{2}$, Hyo Yeol Kim², Seung-Kyu Chung², \\ Kyung Eun Lee², Sang Duk Hong² \\ ' Department of Otorhinolaryngology - Head and Neck Surgery, Korea University College of Medicine, Korea University Ansan \\ Hospital, Ansan, South Korea \\ ${ }^{2}$ Department of Otorhinolaryngology - Head and Neck Surgery, Samsung Medical Center, Sungkyunkwan University School of \\ Medicine, Seoul, Korea \\ ${ }^{3}$ Department of Neurosurgery, Samsung Medical Center, Sungkyunkwan University School of Medicine, Seoul, Korea
}

Rhinology 58: 6, 574 - 580, 2020

https://doi.org/10.4193/Rhin20.020

*Received for publication:

January 13, 2020

Accepted: April 19, 2020

\begin{abstract}
Background: The aim of this study was to compare olfactory function change in patients who underwent endoscopic skull-base surgery.

Methodology: A total of 928 patients were included in this retrospective study. Olfactory function was measured using the nonvalidated Likert scale (0-100), the Cross-Cultural Smell Identification Test (CC-SIT) and the butanol threshold test (BTT). Patients were divided into two groups: an endoscopic trans-sellar approach group $(E T A, n=768)$ and an extended endoscopic endonasal approach group (EEEA, $n=160$ ). The ETA group was sub-divided into Nasoseptal flap (NSF) and no NSF groups.

Results: Non-validated olfactory function significantly worsened in the EEEA and ETA-NSF groups compared with that in the ETAno NSF group for at least 6 months post-operatively. Validated olfactory impairment (BTT and CC-SIT) was also significantly worse in the EEEA and NSF groups compared with that in the ETA-no NSF group 3 months post-operatively. Additionally, the degrees of non-validated and validated olfactory deterioration were not significantly different between the EEEA and ETA-NSF groups. We also found that CC-SIT score changes were significantly impaired in tuberculum sellae meningioma patients than in craniopharyngioma patients.
\end{abstract}

Conclusions: We conclude that NSF was the key factor that led to olfactory impairment after endoscopic skull-base surgery.

Key words: skull base neoplasms, pituitary gland, olfaction disorders

\section{Introduction}

Recently, endoscopic endonasal approaches have been widely used to remove tumors located at the skull base ${ }^{(1,2)}$. Endoscopic endonasal approaches for the treatment of skull-base lesions were reported to be associated with lower morbidity than open approaches ${ }^{(3-8)}$. resulting in the development of new approaches for endoscopic skull-base lesion surgery. An extended endoscopic endonasal approach (EEEA) increases the risk of peri-operative cerebrospinal fluid (CSF) leakage and allows more damage to the adjacent tissue for comfortable handling of surgical instruments and complete tumor resection.

A nasoseptal flap (NSF) is a pedicled neurovascularized mucoperichondrial flap based at the posterior septal branch of the sphenopalatine $\operatorname{artery}^{(9)}$. Since the use of NSF for skull-base reconstruction was introduced, CSF leakage after endoscopic endonasal anterior skull-base surgery has reduced significantly ${ }^{(10)}$. Consequently, NSF has been used to reconstruct skull-base defects in almost all EEEA cases. In a previous study, we reported 
that the post-operative sinonasal-related quality of life (QOL) was significantly worse among patients treated with the EEEA than in those treated with endoscopic trans-sellar approaches (ETA), and that NSF use was the only poor prognostic factor for sinonasal QOL after surgery ${ }^{(11)}$.

Several recent studies reported that endoscopic skull-base surgery might lead to olfactory dysfunction, especially when using an NSF ${ }^{(12-15)}$. However, the sample sizes for these studies were relatively small and the authors did not consider various factors that might be associated with other post-operative morbidities. Therefore, in this study, we compared the degree of non-validated and validated olfactory deterioration between patients treated with EEEA or ETA in a large patient population $(n=928)$. We also conducted subgroup analyses according to NSF usage and we evaluated the frequent suprasellar pathologies of craniopharyngioma (CP) and tuberculum sellae meningioma (TS MMG).

\section{Materials and methods}

\section{Study population}

We retrospectively reviewed data from patients who underwent endoscopic endonasal approaches for the treatment of anterior skull-base lesions at our referral tertiary hospital between June 2012 and July $2019(n=1047)$.

\section{Study design}

Patients with had simultaneous sinonasal disease or a history of previous endoscopic sinus surgery or skull-base surgery were excluded from this study $(n=119)$. Finally, 928 patients who underwent treatment with either ETA $(n=768)$ or EEEA $(n=160)$ were included in this study (Figure 1). All patients underwent pre-operative sinonasal endoscopy and computed tomography (CT) to evaluate the existence of sinonasal disease. This study was approved by the Institutional Ethics Committee of Samsung Medical Center in Seoul, South Korea (Institutional Review Board number: SMC 2019-09-095).

\section{Outcomes}

Olfactory function was evaluated using a non-validated Likert scale (discontinuous scale, $0-100$ ) at 1, 3, and 6 months after surgery. Additionally, the Cross-Cultural Smell Identification Test (CC-SIT) for odor identification and the butanol threshold test (BTT) for odor threshold were performed as validated measurements of olfactory function 3 months after surgery in an outpatient setting ${ }^{(16-18)}$. To evaluate olfactory impairment according to surgery, we compared the degree of pre- and post-operative score changes ( $\Delta 1$-month, $\Delta 3$-month, and $\Delta 6$-month) between the following groups:

1) trans-sellar vs. extended approach: ETA $(n=768)$ vs. EEEA ( $n$ $=160$ )

2) trans-sellar with NSF vs. trans-sellar without NSF: ETA-NSF ( $n=$ 96) vs. ETA-no NSF $(n=672)$

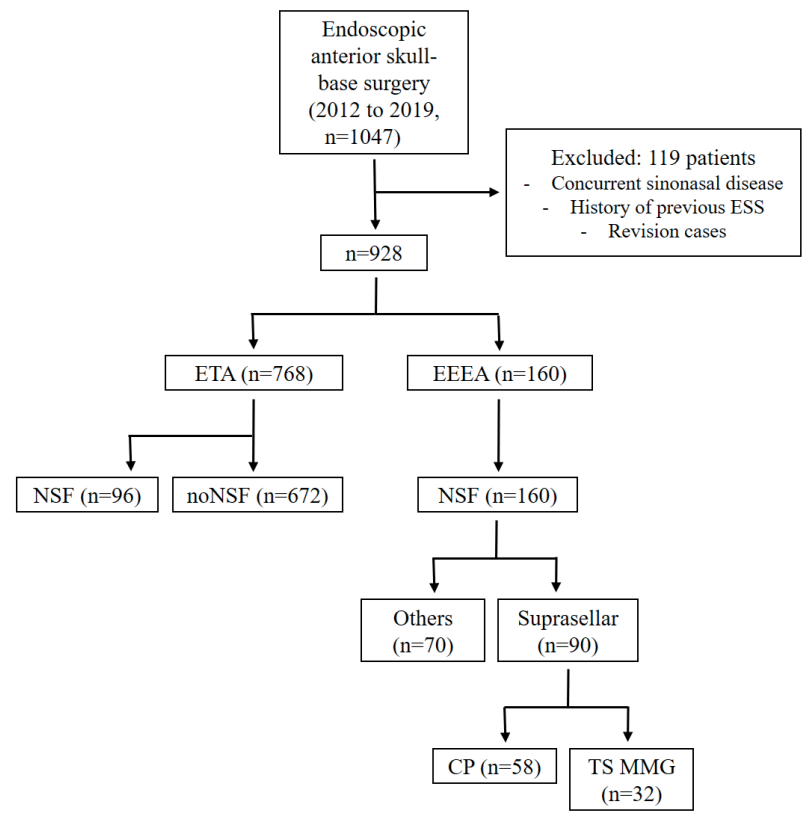

Figure 1. The flow diagram for subgroup classification.

ESS, Endoscopic Sinus Surgery; ETA, Endoscopic Trans-sellar Approach group; EEEA, Extended Endoscopic Endonasal Approach group; NSF, Nasoseptal Flap; CP, Craniopharyngioma; TS MMG, Tuberculum Sellae Meningioma.

3) trans-sellar with NSF vs. extended approach (using NSF in all cases): ETA-NSF ( $n=96)$ vs. EEEA $(n=160)$

4) craniopharyngioma vs. tuberculum sellae meningioma: $C P$ ( $n$ =58) vs. TS MMG $(\mathrm{n}=32)$.

\section{Surgical procedures}

We selected the surgical technique according to the tumor size, location, and characteristics, as well as the amount of CSF leakage.

\section{Endoscopic trans-sellar approach (ETA)}

Although the endoscopic transnasal approach is regarded as a minimally invasive technique, the damage of the adjacent sinonasal structures to obtain a sufficient surgical corridor is inevitable. In our experience, patients who underwent treatment with the trans-septal approach consistently had a relatively clear nasal cavity than those who underwent treatment with the transnasal approach ${ }^{(19)}$. Thus, in our medical center, all ETA procedures were performed by one rhinologist (S.D.H), and one of two neurosurgeons (D.H.N and D.S.K) using modified trans-septal approaches with a 4-mm, 0-degree, 30-degree, or 45-degree endoscope ${ }^{(20)}$.

The nasal cavity was decongested with 1:10,000 epinephrinesoaked cotton pledgets and the nasal septum was infiltrated with a lidocaine-containing epinephrine $(1: 100,000)$ solution. A hemitransfixion incision was performed in the left nasal septal 
Table 1. Patient demographics according to extent of surgery.

\begin{tabular}{|c|c|c|c|c|c|c|}
\hline & & \multicolumn{2}{|c|}{$\operatorname{ETA}(n=768)$} & \multicolumn{2}{|c|}{ EEEA $(n=160)$} & p value \\
\hline \multicolumn{2}{|c|}{ Age, years, mean $\pm S D$} & \multicolumn{2}{|c|}{$50.14 \pm 14.51$} & \multicolumn{2}{|c|}{$50.88 \pm 15.77$} & 0.563 \\
\hline \multirow[t]{2}{*}{ Gender } & Male, N (\%) & 387 & $(50.4 \%)$ & 78 & $(48.8 \%)$ & \multirow{2}{*}{0.706} \\
\hline & Female, N (\%) & 381 & $(49.6 \%)$ & 82 & $(51.3 \%)$ & \\
\hline \multirow[t]{2}{*}{ DM } & Yes, N (\%) & 181 & $(23.6 \%)$ & 40 & $(25 \%)$ & \multirow{2}{*}{0.760} \\
\hline & No, N (\%) & 587 & $(76.4 \%)$ & 120 & $(75 \%)$ & \\
\hline \multirow[t]{2}{*}{ Nasoseptal flap } & Yes, N (\%) & 96 & $(12.5 \%)$ & 160 & $(100 \%)$ & \multirow{2}{*}{$<0.001$} \\
\hline & No, N (\%) & 672 & (87.5\%) & 0 & $(0 \%)$ & \\
\hline \multirow[t]{7}{*}{ Diagnosis } & Pituitary adenoma, N (\%) & 677 & $(88.2 \%)$ & 27 & $(16.9 \%)$ & \multirow{7}{*}{$<0.001$} \\
\hline & RCC, N (\%) & 49 & $(6.4 \%)$ & 5 & $(3.1 \%)$ & \\
\hline & Craniopharyngioma, N (\%) & 0 & $(0 \%)$ & 58 & $(36.3 \%)$ & \\
\hline & Chordoma, N (\%) & 0 & $(0 \%)$ & 20 & $(12.5 \%)$ & \\
\hline & Meningioma (tuberculum), N (\%) & 0 & $(0 \%)$ & 32 & $(20.0 \%)$ & \\
\hline & Meningioma (Olfactory groove) , N (\%) & 0 & $(0 \%)$ & 5 & $(3.1 \%)$ & \\
\hline & Others, N (\%) & 42 & $(5.5 \%)$ & 13 & $(8.1 \%)$ & \\
\hline \multirow[t]{3}{*}{ Baseline olfaction } & Likert scale, mean \pm SD & \multicolumn{2}{|c|}{$88.23 \pm 17.60$} & \multicolumn{2}{|c|}{$84.61 \pm 24.44$} & 0.121 \\
\hline & CC-SIT, mean \pm SD & \multicolumn{2}{|c|}{$9.65 \pm 1.91$} & \multicolumn{2}{|c|}{$8.99 \pm 2.48$} & 0.004 \\
\hline & BTT, mean \pm SD & \multicolumn{2}{|c|}{$5.11 \pm 0.48$} & \multicolumn{2}{|c|}{$4.91 \pm 0.65$} & 0.001 \\
\hline
\end{tabular}

A t test, $\chi^{2}$ test, or Fisher's exact test was used. Bold values indicate statistically significant, DM: Diabetes Mellitus, RCC; Rathke's cleft cyst, ETA; Endoscopic Transsellar Approached group, EEEA; Extended Endoscopic Endonasal Approached group. Values are number of patients (\%) unless noted otherwise.

mucosa and submucoperichondrial and submucoperiosteal dissections were performed toward the rostrum sphenoidale. The anterior septal mucosa was tagged on the left nasal vestibule for comfortable manipulation of instruments. Subsequently, after posterior chondrotomy, the midportion of the bony septum was removed. The sphenoid sinus anterior wall and the inter-sinus septum were gently removed with a Kerrison rongeur and a high-speed drill. A small horizontal incision was made in the right nasal septal mucosa with preservation of the olfactory strip and the endoscope and suction device were inserted through this incision. After tumor removal via a binostril approach, the preserved sphenoid sinus mucosa was repositioned on the sellar floor. When high-flow CSF leakage occurred, an NSF was used for reconstruction. When elevating the NSF, we also designed the incision with preservation of the olfactory strip ${ }^{(21)}$.

\section{Extended endoscopic endonasal approach (EEEA)}

When performing the EEEA, we tried to preserve the middle and superior turbinates; however, due to the tumor size, shape, and location in, some patients, we had to sacrifice the middle and/or superior turbinates to enable surgical manipulation. In all EEEA cases, we performed NSF elevation, when elevating the NSF, superior posterior incisions were made around the olfactory neuroepithelium using a cold-knife instead of an electrocautery device $^{(21)}$. After tumor removal, skull-base reconstruction was performed using intradural and extradural multilayered fascia lata. This was subsequently covered with an NSF. After surgery, the anterior nasal packing was maintained for 3-7 days with Merocel (Medtronic Inc., Minneapolis, MN, USA).

\section{Statistical analysis}

All statistical analyses were approved by the Biostatistics Center of Korea University Ansan Hospital and performed using SPSS 20 for Windows (SPSS, Inc., Chicago, IL, USA) and R 3.4.3 (http:// www.R-project.org; The R Foundation, Vienna, Austria). Categorical variables were compared using the $\chi^{2}$ test or Fisher's exact test, and continuous variables were compared using the Wilcoxon rank-sum test with Bonferroni correction. To control for potential confounding from repeated measures, we performed a generalized estimating equation (GEE) model for the non-validated olfactory impairment variables. A p-value $<0.05$ indicated statistical significance.

\section{Results}

Subject demographics are presented in Tables 1 and 2. The male-to-female ratio was not statistically different between the two groups. A total of 677 patients with pituitary adenoma and 49 patients with Rathke's cleft cyst underwent ETA, and 27 patients with pituitary adenoma, 5 patients with Rathke's cleft cyst, and 128 patients with other tumors (including craniopha- 
Table 2. Patient demographics according to NSF usage in ETA.

\begin{tabular}{|c|c|c|c|c|c|c|}
\hline & & \multicolumn{2}{|c|}{ ETA-NSF $(n=96)$} & \multicolumn{2}{|c|}{ ETA-no NSF $(n=672)$} & p value \\
\hline \multicolumn{2}{|c|}{ Age, years, mean $\pm S D$} & \multicolumn{2}{|c|}{$51.58 \pm 15.07$} & \multicolumn{2}{|c|}{$49.93 \pm 14.43$} & 0.298 \\
\hline \multirow[t]{2}{*}{ Gender } & Male, N (\%) & 45 & $(46.9 \%)$ & 342 & $(50.9 \%)$ & \multirow{2}{*}{0.513} \\
\hline & Female, N (\%) & 51 & $(53.1 \%)$ & 330 & (49.1\%) & \\
\hline \multirow[t]{2}{*}{ DM } & Yes, N (\%) & 31 & $(32.3 \%)$ & 150 & $(22.3 \%)$ & \multirow{2}{*}{0.039} \\
\hline & No, $\mathrm{N}(\%)$ & 65 & $(67.7 \%)$ & 522 & (77.7\%) & \\
\hline \multirow[t]{7}{*}{ Diagnosis } & Pituitary adenoma, N (\%) & 70 & $(79.5 \%)$ & 607 & (91.4\%) & \multirow{7}{*}{$<0.001$} \\
\hline & RCC, N (\%) & 6 & $(6.8 \%)$ & 43 & $(6.5 \%)$ & \\
\hline & Craniopharyngioma, $\mathrm{N}(\%)$ & 0 & $(0 \%)$ & 0 & $(0 \%)$ & \\
\hline & Chordoma, N (\%) & 0 & $(0 \%)$ & 0 & $(0 \%)$ & \\
\hline & Meningioma (tuberculum), N (\%) & 0 & $(0 \%)$ & 0 & $(0 \%)$ & \\
\hline & Meningioma (Olfactory groove), $\mathrm{N}(\%)$ & 0 & $(0 \%)$ & 0 & $(0 \%)$ & \\
\hline & Others, N (\%) & 20 & $(13.7 \%)$ & 22 & $(2.1 \%)$ & \\
\hline \multirow[t]{3}{*}{ Baseline olfaction } & Likert scale, mean \pm SD & \multicolumn{2}{|c|}{$87.43 \pm 18.88$} & \multicolumn{2}{|c|}{$88.32 \pm 17.45$} & 0.688 \\
\hline & CC-SIT, mean \pm SD & \multicolumn{2}{|c|}{$9.66 \pm 2.07$} & \multicolumn{2}{|c|}{$9.65 \pm 1.89$} & 0.979 \\
\hline & $\mathrm{BTT}$, mean $\pm \mathrm{SD}$ & \multicolumn{2}{|c|}{$5.13 \pm 0.48$} & \multicolumn{2}{|c|}{$5.10 \pm 0.48$} & 0.618 \\
\hline
\end{tabular}

A t test, $\chi^{2}$ test, or Fisher's exact test was used. Bold values indicate statistically significant. DM: Diabetes Mellitus, RCC; Rathke's cleft cyst, ETA; Endoscopic Transsellar Approached group, EEEA; Extended Endoscopic Endonasal Approached group. Values are number of patients (\%) unless noted otherwise.

ryngioma, chordoma, and meningioma) underwent EEEA. The baseline olfaction was different between both groups according to the extent of surgery (ETA vs EEEA). Therefore we evaluated the olfactory impairment as the amount of olfactory score change after surgery.

Non-validated olfactory function change according to surgery Non-validated olfactory impairment according to Likert scale

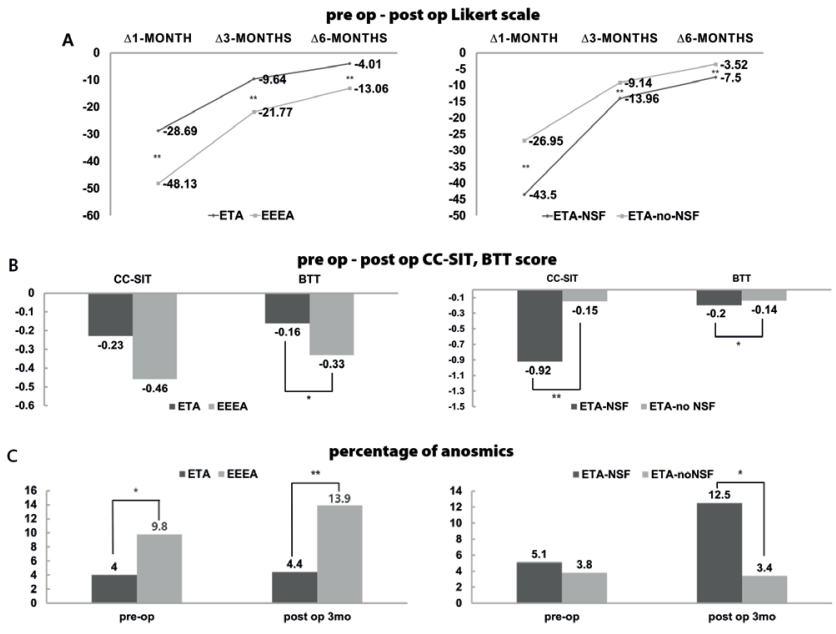

Figure 2. Degree of (A) non-validated olfactory impairment based on Likert scale and (B) validated olfactory impairment based on CC-SIT and BTT scores according to the surgical corridors after surgery. (C) The percentage of patients who were diagnosed with anosmia (patients with CC-SIT score $\leq 5) .{ }^{*} p<0.05,{ }^{* *} p<0.001$. values (0-100) was significantly worse in the EEEA group than in the ETA group at 1, 3 and 6 months post-operatively. We also found that non-validated olfactory function was significantly worse in the ETA-NSF group than in the ETA-no NSF group at 1, 3 , and 6 months post-operatively (Figure 2).

We also performed a comparison between the ETA-NSF and EEEA groups to exclude effects associated with NSF usage. The degree of deterioration according to non-validated olfactory function was not significantly different between the two groups at 1, 3 and 6 months post-operatively (Table 3).

Lastly, after undergoing the transplanum approach for suprasellar tumors, non-validated olfactory function impairment was not significantly different at 1,3, and 6 months post-operatively between CP and TS MMG groups (Table 3 ).

Validated olfactory function change according to surgery We assessed olfactory impairment according to surgery 3 months post-operatively. The degree of BTT score change in the EEEA group was significantly worse than that in the ETA group. However, the degree of CC-SIT score change was not significantly different between the two groups. Additionally, the validated olfaction change according to the CC-SIT and BTT scores was significantly more impaired in the ETA-NSF group than in the ETA-no NSF group. Moreover, we assessed the percentage of anosmics (patients with CC-SIT score $\leq 5$ ) in the groups at baseline and after surgery. We found that the percentage of anosmics was significantly higher in the ETA-no NSF group than in 
Table 3. Postoperaitve olfactory function impairment according to endoscopic transsellar and expanded endoscopic endonasal approach in nasoseptal flap reconstructed subjects, and craniopharyngioma and tuberculum sellae meningioma in extended endoscopic endonasal approached subjects.

\begin{tabular}{|c|c|c|c|c|c|c|c|c|c|c|c|c|}
\hline & \multicolumn{3}{|c|}{ Baseline olfaction } & \multicolumn{3}{|c|}{$\Delta 1$-month } & \multicolumn{3}{|c|}{$\Delta 3$-months } & \multicolumn{3}{|c|}{$\Delta 6$-months } \\
\hline & ETA-NSF & EEEA & $\mathbf{p}$ & ETA-NSF & EEEA & $\mathbf{p}$ & ETA-NSF & EEEA & $\mathbf{p}$ & ETA-NSF & EEEA & $\mathbf{p}$ \\
\hline $\begin{array}{l}\text { Likert } \\
\text { scale }\end{array}$ & $\begin{array}{c}87.43 \\
\pm 18.88\end{array}$ & $\begin{array}{c}84.61 \\
\pm 24.44\end{array}$ & 0.407 & $\begin{array}{c}43.50 \\
\pm 33.69\end{array}$ & $\begin{array}{c}48.14 \\
\pm 36.51\end{array}$ & $>0.999$ & $\begin{array}{c}13.96 \\
\pm 20.41\end{array}$ & $\begin{array}{c}21.77 \\
\pm 27.72\end{array}$ & 0.336 & $\begin{array}{c}7.50 \\
\pm 22.03\end{array}$ & $\begin{array}{c}13.06 \\
\pm 22.49\end{array}$ & 0.678 \\
\hline $\mathrm{CC}-\mathrm{CIT}$ & $\begin{array}{c}9.66 \\
\pm 2.07\end{array}$ & $\begin{array}{c}8.99 \\
\pm 2.48\end{array}$ & 0.044 & & & & $\begin{array}{c}0.92 \\
\pm 2.02\end{array}$ & $\begin{array}{c}0.46 \\
\pm 2.01\end{array}$ & 0.159 & & & \\
\hline \multirow[t]{2}{*}{ BTT } & $\begin{array}{c}5.13 \\
\pm 0.48\end{array}$ & $\begin{array}{c}4.91 \\
\pm 0.65\end{array}$ & 0.010 & & & & $\begin{array}{c}0.20 \\
\pm 0.33\end{array}$ & $\begin{array}{c}0.33 \\
\pm 0.73\end{array}$ & 0.966 & & & \\
\hline & $\mathrm{CP}$ & TS MNG & $\mathrm{p}$ & $\mathrm{CP}$ & TS MNG & $\mathrm{p}$ & $\mathrm{CP}$ & TS MNG & $\mathrm{p}$ & $\mathrm{CP}$ & TS MNG & $\mathrm{p}$ \\
\hline $\begin{array}{l}\text { Likert } \\
\text { scale }\end{array}$ & $\begin{array}{c}87.61 \\
\pm 25.35\end{array}$ & $\begin{array}{c}79.13 \\
\pm 28.43\end{array}$ & 0.217 & $\begin{array}{c}48.33 \\
\pm 38.11\end{array}$ & $\begin{array}{c}50.61 \\
\pm 33.56\end{array}$ & 0.811 & $\begin{array}{c}21.18 \\
\pm 29.77\end{array}$ & $\begin{array}{c}22.92 \\
\pm 21.96\end{array}$ & 0.809 & $\begin{array}{c}13.54 \\
\pm 22.67\end{array}$ & $\begin{array}{c}17.86 \\
\pm 28.60\end{array}$ & 0.611 \\
\hline CC-CIT & $\begin{array}{c}9.10 \\
\pm 2.59\end{array}$ & $\begin{array}{c}9.08 \\
\pm 2.32\end{array}$ & 0.976 & & & & $\begin{array}{c}0.08 \\
\pm 1.92\end{array}$ & $\begin{array}{c}1.18 \\
\pm 1.71\end{array}$ & 0.031 & $\begin{array}{c}0.00 \\
\pm 1.00\end{array}$ & & \\
\hline BTT & $\begin{array}{c}5.00 \\
\pm 0.40\end{array}$ & $\begin{array}{c}4.93 \\
\pm 0.64\end{array}$ & 0.586 & & & & $\begin{array}{c}0.25 \\
\pm 0.64\end{array}$ & $\begin{array}{c}0.42 \\
\pm 0.89\end{array}$ & 0.407 & $\begin{array}{c}0.13 \\
\pm 0.18\end{array}$ & & \\
\hline
\end{tabular}

Wilcoxon rank sum test with the Bonferroni correction was used, Data are mean \pm SD, Bold values indicate statistically significant. ETA: Endoscopic Transsellar Approached group; EEEA: Extended Endoscopic Endonasal Approached group; CP: Craniopharyngioma; TS MNG: Tuberculum sellae meningioma.

the ETA-NSF group (Figure 2). We did not find a difference in validated olfactory change according to the CC-SIT and BTT scores between the ETA-NSF and EEEA groups. Lastly, the degree of CCSIT score change in the TS MMG group was significantly worse than that in the CP group. The degree of BTT score change was not significantly different between the two groups (Table 3).

\section{Discussion}

This is the largest study $(n=928)$ to compare the degree of olfactory impairment between EEEA and ETA approaches. Moreover, to our knowledge, because we performed subgroup analyses, this is the first study to report that post-operative olfactory impairments worsened when extended surgical corridors were used or in association with NSF usage.

We found that non-validated (Likert scale) olfaction was significantly worse in the EEEA group than in the ETA group 1, 3, and 6 months after surgery. Furthermore, validated olfactory functions (BTT) were significantly worse in the EEEA group than in the ETA group at 3 months post-operatively. Moreover, to confirm that the negative effect on olfactory function was due to NSF usage, we compared olfactory impairment in patients who underwent ETA with and without NSF. From this assessment, we found that the degree of non-validated and validated olfactory function was significantly worse in the NSF group. Several studies have examined the effect of NSF usage in subjects who were treated using an endoscopic approach and have reported conflicting results. Tam et al. ${ }^{(14)}$ performed a randomized controlled study involving 20 subjects who underwent endoscopic transsphenoidal pituitary surgery for pituitary adenoma. They reported that
NSF use can worsen olfactory impairment until at least 6 months after surgery. Additionally, Upadhyay et al. ${ }^{(15)}$ conducted a prospective study involving 50 subjects treated for skull-base tumors using an extended endoscopic approach, and showed that NSF use was associated with a short-term ( 6 weeks post-operatively) negative impact on olfaction. However, in a prospective cohort study by Chaaban et al. ${ }^{(12)}$ involving 33 subjects, they reported that NSF use did not adversely affect post-operative olfactory function. Although, our study involved the retrospective review of medical records, we deliberately collected olfactory data on a planned schedule. Furthermore, this study is the largest study to compare olfactory outcomes after endoscopic skull-base surgery. We conclude that NSF is a key factor that causes the deterioration of olfaction after anterior skull-base surgery, and the deterioration lasted for at least 3 months.

In our study, all patients in the EEEA group underwent reconstruction of skull-base defects using NSF. Thus, we compared olfactory impairment between the ETA-NSF and EEEA groups in NSF used patients. To the best of our knowledge, no study in the English literature has compared these groups. We did not find significant differences in non-validated and validated olfactory impairment between the ETA-NSF and EEEA groups. Finally, we found that NSF usage was the key factor that cause olfactory impairment after anterior skull-base surgery. Additionally, further impairment of olfactory function in the EEEA and ETA groups was due to NSF usage. Thus, clinicians note that NSF usage might worsen olfactory impairment. In some cases, NSF usage is mandatory for the reconstruction of skull-base defects. Therefore, clinicians should explain the risk of olfactory impairment to 


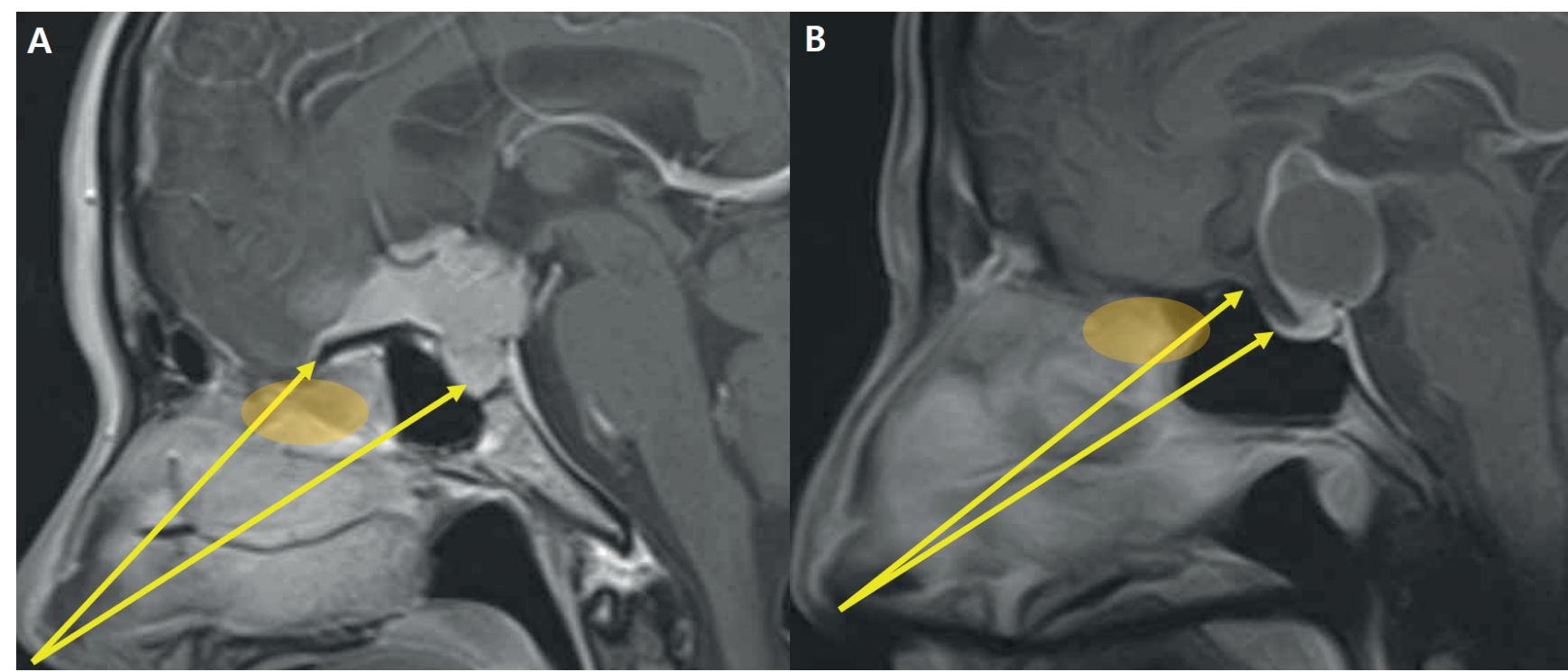

Figure 3. Arrow indicates imaginary line during surgery to treat (A) tuberculum sellae meningioma and (B) craniopharyngioma. The endoscopic approach for treating tuberculum sellae meningioma required more superior and anterior dissection of the sinonasal tract near the neuroepithelium (orange ellipse) and had the potential risk of causing olfactory deterioration.

patients when NSF usage is required.

We also compared the olfactory outcomes between two different types of suprasellar tumors: craniopharyngiomas and tuberculum sellae meningiomas. No previous study has compared morbidities according to tumor pathology. Although this analysis was conducted using a relatively small sample (CP $=32$, TS MMG $=58$ ), we believe that surgical approaches for TS MMG require further manipulation of the anterior skull-base area, thus causing more trauma to the olfactory neuroepithelium than surgical approaches for CP (Figure 3). The CC-SIT score for olfactory impairment was significantly worse in the TS MMG group 3 months post-operatively than that in the CP group. We also found that the mean score changes for other parameters also worsened in the TS MMG group, even though these changes were not significant. Therefore, we suggest that physicians should consider the possibility of the occurrence of post-operative olfactory deterioration when selecting their surgical approach (transcranial vs. endonasal), especially in TS meningioma cases.

This study has some limitations. First, although we evaluated non-validated olfactory function until 6 months after surgery, the final validated olfactory function tests were performed at 3 months post-surgery. A longer follow-up period could yield more information and might also alter the results. However, several researchers have reported that the sinonasal mucosa and olfactory function had mostly stabilized after 3 months $s^{(22,23)}$. Therefore, we must also consider that long-term validated olfactory function may not be significantly different between the surgery types, as is the case 3 months after surgery. Second, some comorbidities such as diabetes mellitus (DM) and neu- rologic deficits may causes olfactory impairment. In this study, we found that the prevalence of DM was significantly higher in the ETA-NSF group than in the ETA-no NSF group. Furthermore, we did not consider neurologic deficits as confounding factors during data collection. Although, we need to investigate the existing comorbidities, this study is a retrospective study. Therefore, we do not have data on the concurrent neurologic deficits among patients. Thus, our study might have some confounding bias. Third, in our study subgroups, the number of subjects in the ETA group was 4.8 times higher than the number of subjects in EEEA group. This implies the risk of lack of potency for EEEA subgroup and it is one of limitations of our study. Fourth, in the ETA group, high flow CSF leakage that required an NSF occurred during surgery for treating more aggressive tumors. Therefore, we have to manipulate more aggressively. It could be an independent potential risk factor for post-operative olfactory dysfunction. During suprasellar tumor surgery, wider surgical corridors were required in TS MMG patients than in CP patients. This more aggressive dissection resulted in severe olfactory loss.

\section{Conclusion}

Non-validated and validated olfactory function were significantly worse in patients treated by EEEA than by ETA. Furthermore, NSF use causes non-validated olfactory impairment until at least 6 months after surgery. We suggest that NSF usage was the key factor that cause olfactory impairment after endoscopic skullbase surgery and further impairment of olfactory function after EEEA and ETA was due to NSF use. Therefore, clinicians should use NSF only when absolutely necessary. Furthermore, when NSF usage is planned, physicians must inform patients about 
the possibility of olfaction deterioration after the surgery.

\section{Acknowledgements}

None.

\section{Authorship contribution}

MYS and SDH conceived and drafted the study, and MYS and $\mathrm{SDH}$ wrote the final manuscript. KEL contributed to the acquisition of the data. MYS, DHN, DSK, HYK SKC, and SDH contributed to the study design, and made critical revisions. MYS, SHL, YN, YGJ, and SDH contributed to the analysis and interpretation of data. All of the authors have read and approved the final manuscript.

\section{Conflict of interest}

The authors report no conflicts of interest concerning the materials or methods used in this study or the findings described in this paper.

\section{References}

1. Doglietto F, Prevedello DM, Jane JA, Jr., Han J, Laws ER, Jr. Brief history of endoscopic transsphenoidal surgery--from Philipp Bozzini to the First World Congress of Endoscopic Skull Base Surgery. Neurosurg Focus. 2005; 19: E3.

2. Prevedello DM, Doglietto F, Jane JA, Jr. Jagannathan J, Han J, Laws ER, Jr. History of endoscopic skull base surgery: its evolution and current reality. J Neurosurg. 2007; 107 206-213.

3. Adams CB, Burke CW. Current modes of treatment of pituitary tumours. $\mathrm{Br} J$ Neurosurg. 1993; 7: 123-127

4. Cappabianca P, Cavallo LM, Colao A, et al. Endoscopic endonasal transsphenoidal approach: outcome analysis of 100 consecutive procedures. Minim Invasive Neurosurg. 2002; 45: 193-200.

5. Field M, Spector B, Lehman J. Evolution of endoscopic endonasal surgery of the skull base and paranasal sinuses. Atlas Oral Maxillofac Surg Clin North Am. 2010; 18: 161-179.

6. Jardeleza C, Seiberling K, Floreani S Wormald PJ. Surgical outcomes of endoscopic management of adenocarcinoma of the sinonasal cavity. Rhinology. 2009; 47 354-361.

7. Komotar RJ, Starke RM, Raper DM, Anand VK, Schwartz TH. Endoscopic skull base surgery: a comprehensive comparison with open transcranial approaches. $\mathrm{Br}$ Neurosurg. 2012; 26: 637-648.

8. Nasseri SS, Kasperbauer JL, Strome SE, McCaffrey TV, Atkinson JL, Meyer FB. Endoscopic transnasal pituitary surgery: report on 180 cases. Am J Rhinol. 2001; 15: 281-287.

9. Hadad G, Bassagasteguy L, Carrau RL, et al. A novel reconstructive technique after endoscopic expanded endonasal approaches: vascular pedicle nasoseptal flap. Laryngoscope. 2006; 116: 1882-1886.

10. Zanation AM, Carrau RL, Snyderman $\mathrm{CH}$, et al. Nasoseptal flap reconstruction of high flow intraoperative cerebral spinal fluid leaks during endoscopic skull base surgery. Am J Rhinol Allergy. 2009; 23: 518-521.

11. Seo MY, Nam DH, Kong DS, et al. Quality of life after extended versus transsellar endoscopic skull base surgery from 767 patients. Laryngoscope. 2019; 129: 1318-1324.

12. Chaaban MR, Chaudhry AL, Riley KO, Woodworth BA. Objective assessment of olfaction after transsphenoidal pituitary surgery. Am J Rhinol Allergy. 2015; 29: 365-368.

13. Rioja E, Bernal-Sprekelsen M, Enriquez $\mathrm{K}$, et al. Long-term outcomes of endoscopic endonasal approach for skull base surgery: a prospective study. Eur Arch Otorhinolaryngol. 2016; 273: 1809-1817.

14. Tam S, Duggal N, Rotenberg BW. Olfactory outcomes following endoscopic pituitary surgery with or without septal flap reconstruction: a randomized controlled trial. Int Forum Allergy Rhinol. 2013; 3: 62-65.

15. Upadhyay S, Buohliqah L, Dolci RLL, Otto BA, Prevedello DM, Carrau RL. Periodic olfactory assessment in patients undergoing skull base surgery with preservation of the olfactory strip. Laryngoscope. 2017; 127: 1970-1975.

16. Doty RL, Marcus A, Lee WW. Development of the 12-item Cross-Cultural Smell Identification Test (CC-SIT). Laryngoscope. 1996; 106: 353-356.

17. Hong SC, Yoo YS, Kim ES, et al. Development of KVSS Test (Korean Version of Sniffin' Sticks Test). Korean J Otorhinolaryngol-Head Neck Surg. 1999; 42: 855-860.

18. Smith DV. Assessment of patients with taste and smell disorders. Acta Otolaryngol Suppl. 1988; 458: 129-133.

19. Hong SD, Nam DH, Seol HJ, et al. Endoscopic binostril versus transnasal transseptal microscopic pituitary surgery: Sinonasal quality of life and olfactory function. Am J Rhinol Allergy. 2015; 29: 221-225.

20. Hong SD, Nam DH, Kong DS, Kim HY, Chung SK, Dhong HJ. Endoscopic Modified Transseptal Transsphenoidal Approach for Maximal Preservation of Sinonasal Quality of Life and Olfaction. World Neurosurg. 2016; 87: 162-169.

21. Hong SD, Nam DH, Park J, Kim HY, Chung SK, Dhong HJ. Olfactory outcomes after endoscopic pituitary surgery with nasoseptal "rescue" flaps: electrocautery versus cold knife. Am J Rhinol Allergy. 2014; 28: 517-519.

22. de Almeida JR, Snyderman CH, Gardner PA, Carrau RL, Vescan AD. Nasal morbidity following endoscopic skull base surgery: a prospective cohort study. Head Neck. 2011; 33: 547-551.

23. Hart CK, Theodosopoulos PV, Zimmer LA. Olfactory changes after endoscopic pituitary tumor resection. Otolaryngol Head Neck Surg. 2010; 142: 95-97.

Sang Duk Hong, MD. PhD

Department of Otorhinolaryngology

- Head and Neck Surgery

Samsung Medical Center

Sungkyunkwan University School of

Medicine

81 Irwon-ro, Gangnam-gu,

Seoul,

Korea, 06351

Tel: +82-2-3410-3579

Fax: +82-2-3410-3879

E-mail:kkam97@gmail.com 